recent advances in phytochemistry

volume 30

\title{
Phytochemical \\ Diversity and \\ Redundancy in \\ Ecological Interactions
}




\section{RECENT ADVANCES IN PHYTOCHEMISTRY}

Proceedings of the Phytochemical Society of North America

General Editor: John T. Romeo, University of South Florida, Tampa, Florida

Recent Volumes in the Series:

Volume 21 The Phytochemical Effects of Environmental Compounds Proceedings of the Twenty-sixth Annual Meeting of the Phytochemical Society of North America, College Park, Maryland, July, 1986

Volume 22 Opportunities for Phytochemistry in Plant Biotechnology Proceedings of the Twenty-seventh Annual Meeting of the Phytochemical Society of North America, Tampa, Florida, June, 1987

\section{Volume 23 Plant Nitrogen Metabolism}

Proceedings of the Twenty-eighth Annual Meeting of the Phytochemical Society of North America, lowa City, lowa, June, 1988

Volume 24 Biochemistry of the Mevalonic Acid Pathway to Terpenoids Proceedings of the Twenty-ninth Annual Meeting of the Phytochemical Society of North America, Vancouver, British Columbia, Canada, June, 1989

\section{Volume 25 Modern Phytochemical Methods}

Proceedings of the Thirtieth Annual Meeting of the Phytochemical Society of North America, Quebec City, Quebec, Canada, August, 1990

Volume 26 Phenolic Metabolism in Plants

Proceedings of the Thirty-first Annual Meeting of the Phytochemical Society of North America, Fort Collins, Colorado, June, 1991

Volume 27 Phytochemical Potential of Tropical Plants Proceedings of the Thirty-second Annual Meeting of the Phytochemical Society of North America, Miami Beach, Florida, August, 1992

Volume 28 Genetic Engineering of Plant Secondary Metabolism Proceedings of the Thirty-third Annual Meeting of the Phytochemical Society of North America, Pacific Grove, California, June-July, 1993

Volume 29 Phytochemistry of Medicinal Plants Proceedings of the Thirty-fourth Annual Meeting of the Phytochemical Society of North America, Mexico City, Mexico, August, 1994

\section{Volume 30 Phytochemical Diversity and Redundancy in Ecological Interactions \\ Proceedings of the Thirty-fifth Annual Meeting of the Phytochemical Society of North America, Sault Ste. Marie, Ontario, Canada, August, 1995}

A Continuation Order Plan is available for this series. A continuation order will bring delivery of each new volume immediately upon publication. Volumes are billed only upon actual shipment. For further information please contact the publisher. 


\title{
recent advances in phytochemistry
}

\section{volume 30}

\section{Phytochemical \\ Diversity and \\ Redundancy in \\ Ecological Interactions}

\author{
Edited by \\ John T. Romeo \\ University of South Florida \\ Tampa, Florida
}

James A. Saunders

USDA

Beltsville, Maryland

and

Pedro Barbosa

University of Maryland

College Park, Maryland 
On file

Cover photographs: Imago and larva of Zygaena trifolii which possesses a cyanogenic system similar to that of its host plant Lotus. It both accumulates linamarin and lotaustralin from the host and synthesizes the compounds de novo-redundancy?

Proceedings of the Thirty-Fifth Annual Meeting of the Phytochemical Society of North America on Phytochemical Diversity and Redundancy in Ecological Interactions, held August 12-16, 1995, in Sault Ste. Marie, Ontario, Canada

ISBN 978-1-4899-1756-0 ISBN 978-1-4899-1754-6 (eBook)

DOI 10.1007/978-1-4899-1754-6

(C) 1996 Springer Science+Business Media New York

Originally published by Plenum Press, New York in 1996.

Softcover reprint of the hardcover 1st edition 1996

All rights reserved

10987654321

No part of this book may be reproduced, stored in a retrieval system, or transmitted in any form or by any means, electronic, mechanical, photocopying, microfilming, recording, or otherwise, without written permission from the Publisher 


\section{PREFACE}

Diversity within and among living organisms is both a biological imperative and a biological conundrum. Phenotypic and genotypic diversity is the critical currency of ecological interactions and the evolution of life. Thus, it is not unexpected to find vast phytochemical diversity among plants. However, among the most compelling questions which arise among those interested in ecological phytochemistry is the extent, nature, and reasons for the diversity of chemicals in plants.

The idea that natural products (secondary metabolites) are accidents of metabolism and have no biological function is an old one which has resurfaced recently under a new term "redundancy." Redundancy in the broader sense can be viewed as duplication of effort. The co-occurrence of several classes of phytochemicals in a given plant may be redundancy. Is there unnecessary duplication of chemical defense systems and if so, why? What selective forces have produced this result? On the other hand, why does the same compound often have multiple functions?

At a symposium of the Phytochemical Society of North America held in August 1995, in Sault Ste. Marie, Ontario, Canada, the topic "Phytochemical Redundancy in Ecological Interactions" was discussed. The chapters in this volume are based on that symposium. They both stimulate thought and provide some working hypotheses for future research. It is being increasingly recognized that functional diversity and multiplicity of function of natural products is the norm rather than the exception.

Berenbaum and Zangerl set the stage as they eloquently make the case that function in nature cannot be equated with biological kill in bioassays. With examples drawn from a single class of compounds, the furancoumarins, evidence for diverse functions, multiple functions, and the importance of synergism in mixtures is provided. Lindroth and Hwang, concentrating on a single genus of plants, the aspens, show how bioactivity of terpenoids and phenolics spans not only families, but kingdoms. Similar examples of multiplicity of function are provided by Renwick from Pieris butterfly/glucosinolate studies, and by Siegel and Bush from alkaloids in endophytic grasses. 
Hammerschmidt and Schultz draw the parallel between insecticidal activity and defense against pathogens, emphasizing that different approaches to problems among plant/insect ecologists and plant pathologists have heretofore obscured the idea of the same or similar compounds having a range of biological function. Both groups may gain insight from studies of the other's discipline. Isman et al., in a discussion of compounds from the neem tree, emphasize the importance of nontoxic compounds which nonetheless can enhance toxicity. This is a relatively new concept which further complicates already complicated synergistic effects. It needs further attention. Cates' long-term study of the unique pine/sawfly interaction demonstrates convincingly that interactions mediated by chemicals are never simple, and that many relatively common natural products act in concert, possibly with common products of primary metabolism.

Nahrstedt's paper showing that an insect makes a toxic cyanogen which it can also accumulate from its host plant puts still a different twist on the debate. Is such duplication of effort redundancy in the narrow sense or an expanded functional role? In the same vein, the diversity of mechanisms which are responsible for systemic and non-systemic resistance to pathogens can be viewed as either "redundant" or adaptive to a variety of selective pressures. The papers by Constabel et al. and Uknes et al. are both enlightening and perplexing in this regard.

Finally, the ideas of complexity theory, made accessible in the paper by Jarvis and Miller, and the redundancy defense, here further refined by Firn and Jones, provoke a lively debate which ultimately may help ecologists and phytochemists alike refine their ideas about the ecological functions of natural products. While the papers in this volume go a long way towards solidifying the case for natural product functional diversity and multiplicity, they also emphasize a complexity of nature that is perhaps too convoluted and too varied to be explained by any single term, be it diversity, redundancy, or any new one on the horizon!

The senior editor expresses gratitude to Dawn McGowan for excellent technical expertise in the preparation of this volume. We have made an effort in all papers in this volume to emphasize the term "natural product" in lieu of the outdated term "secondary metabolite."

John T. Romeo, University of South Florida

James A. Saunders, USDA, Beltsville

Pedro Barbosa, University of Maryland 


\section{CONTENTS}

1. Phytochemical Diversity: Adaptation or Random Variation? . . . . . 1

May R. Berenbaum and Arthur R. Zangerl

2. Diversity, Redundancy, and Multiplicity in Chemical Defense

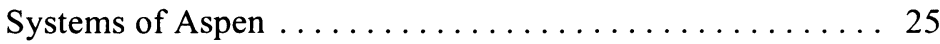

Richard L. Lindroth and Shaw-Yhi Hwang

3. Diversity and Dynamics of Crucifer Defenses against Adults and

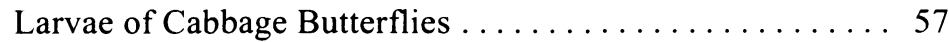

J. A. A. Renwick

4. Defensive Chemicals in Grass-Fungal Endophyte Associations . . . . 81

Malcolm R. Siegel and Lowell P. Bush

5. Multiple Defenses and Signals in Plant Defense against Pathogens

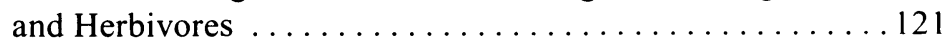

Ray Hammerschmidt and Jack C. Schultz

6. Phytochemistry of the Meliaceae: So Many Terpenoids, So Few

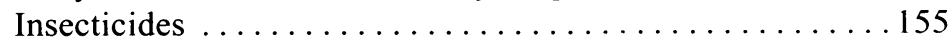

Murray B. Isman, Hideyuki Matsuura, Shawna MacKinnon, Tony Durst, G. H. Neil Towers, and John T. Arnason

7. The Role of Mixtures and Variation in the Production of

Terpenoids in Conifer-Insect-Pathogen Interactions . . . . . 179

Rex G. Cates

8. Relationships between the Defense Systems of Plants and Insects:

The Cyanogenic System of the Moth Zygaena trifolii . . . 217

Adolf Nahrstedt 
9. Polyphenol Oxidase as a Component of the Inducible Defense Response in Tomato against Herbivores ........... 231

C. Peter Constabel, Daniel R. Bergey, and Clarence A. Ryan

10. The Role of Benzoic Acid Derivatives in Systemic Acquired Resistance ........................... 253

Scott Uknes, Shericca Morris, Bernard Vernooij, and John Ryals

11. Natural Products, Complexity, and Evolution

Bruce B. Jarvis and J. David Miller

12. An Explanation of Secondary Product "Redundancy" ........... 295

Richard D. Firn and Clive G. Jones

Index 